\title{
O JOGO DE INTERMEDIAÇÕES ENUNCIATIVAS NO ROMANCE DE ALAN PAULS
}

\author{
THE PLAY ON ENUNCIATIVE INTERMEDIATIONS \\ IN ALAN PAULS' NOVEL
}

\author{
Maria de Lourdes Ortiz Gandini Baldan \\ UNESP - Universidade Estadual Paulista (FCLAr) ${ }^{1}$
}

\begin{abstract}
RESUMO: O romance $O$ passado (2003) de Alan Pauls apresenta muitas isotopias que mereceriam ser investigadas: há uma construção variada de relacionamentos amorosos entre os personagens com sentimentos diferentes, que permitiriam um mapeamento de paixões a serem estudadas; há uma atividade de tradução (ofício desempenhado por Rimini e Carmen) que engendra contornos muito ricos na reflexão sobre a atividade literária que está se realizando. E há a presença de Jeremy Riltse, artista plástico criado por esse discurso, com uma poética completa. Um trabalho com a dimensão que este pretende ter, não conseguiria tratar de todas elas. Ficamos apenas com a última, ou seja, verificar como o artista plástico ficcional e sua obra singular funcionam no romance.
\end{abstract}

PALAVRAS-CHAVE: Enunciação; Narrativa Contemporânea; Literatura e outras Artes.

ABSTRACT: The novel $O$ passado (2003) by Alan Pauls presents many isotopies which would deserve to be investigated: there is a varied construction of loving relationships among the characters, who reveal different feelings, that would allow a mapping of passions to be studied; there is an activity of translation (role performed by Rimini and Carmen) that engenders a very rich reflection on the literary activity which is taking place. There is also the presence of a visual artist, Jeremy Riltse, revealing a poetic work which was created by this discourse. Due to the dimension that a research of this kind would require, it is not possible to deal with all the isotopies. Thus, the last one was chosen to be investigated, that is, to verify how the fictional visual artist and his singular work operate in the novel.

KEYWORDS: Enunciation, Contemporary Narrative, Literature and other Arts.

\section{Introdução}

O romance $O$ passado ${ }^{2}$ do escritor argentino Alan Pauls, publicado na Argentina em 2003, e no Brasil em 2007, com tradução de Josely Vianna Baptista, é o quarto romance do autor, ganhador do prestigioso prêmio Herralde em 2003 e filmado por Hector

\footnotetext{
${ }^{1}$ Universidade Estadual Paulista - Faculdade de Ciências e Letras - Araraquara - Departamento de Literatura Caixa Postal: 174 - CEP: 14800-901 - e-mail: udeogb@ fclar.unesp.br

${ }^{2}$ Publicado pela Cosac Naify, São Paulo, em 2007, com 480 páginas. Essa será a edição usada para as citações do trabalho. 
Babenco em 2007. Antes disso, ele publicara El pudor Del pornógrafo (1984), El coloquio (1990) e Wasabi (1994), este último lançado no Brasil pela Iluminuras. Além de romances e contos, o escritor escreveu ensaios sobre Manuel Puig, Jorge Luis Borges e Lino Palácio. Tendo sido professor de Teoria Literária na Universidade de Buenos Aires, Alan Pauls foi fundador da revista Lecturas Críticas e subeditor do suplemento dominical de Pagina 12 e chefe de redação da revista Pagina 30. É conhecida sua atividade como roteirista e crítico de cinema, o que pode explicar a forma sofisticada com que o escritor cria pontos de vista narrativos, enquadramentos e intermediações enunciativas.

$\mathrm{Na}$ época do lançamento da obra no Brasil, Miguel Sanches Neto publicou uma resenha ${ }^{3}$ inventariando títulos possíveis para o romance: "A Mulher Zumbi", por causa da natureza fantasmagórica da personagem Sofia e seu amor patológico pelo ex-namorado Rimini, ou "Ex" pela presença incessante da namorada nas relações futuras de Rimini ou ainda "Torrente contínua", baseada em uma fala de um personagem que diz: "O amor é uma torrente contínua". Mas a opção pelo título O passado valorizou mais de uma isotopia narrativa ( e não apenas a do amor obsessivo) e deu à memória - razão de existir do passado o poder agregador de garantir alguma constância no discurso, repleto de lacunas, anacronias e fragmentação. O filme, de mesmo nome, de Hector Babenco, ao transformar a narrativa literária em linguagem fílmica, escolhe algumas isotopias, em detrimento de outras que poderiam ser exploradas na narrativa cinematográfica. Uma isotopia que o romance explora é a vida e obra do pintor fictício Jeremy Riltse em sua relação com as outras personagens. $\mathrm{O}$ filme não trata dessa questão da mesma forma que o livro; no filme, a arte pictural tem grande importância, mas não tem a funcionalidade narrativa que podemos ler no romance. Além de uma metáfora sobre a arte, sobre o amor patológico, sobre a obsessão criativa, sobre a tradução, as artes plásticas dão ao romance um olhar, um ponto de vista, uma forma intermediada de enunciar. Sob a impressão de lentes da fotografia ou sob a expressão das cores e texturas da pintura, o narrador vai construindo, aos poucos, fragmentariamente, um discurso que reconstrói o passado que o define. O estilo compulsivo de narrar, como um jorro de humores humanos, não impede que as cenas sejam construídas por sofisticados enquadramentos enunciativos. O objetivo deste trabalho é compreender a funcionalidade narrativa da pintura de Jeremy Riltse, personagem criado por esse discurso e que só existe nele.

\section{1- O narrar e o mostrar}

O artista plástico Jeremy Riltse, nascido em 1917 e morto em 1995, com vida e obra cheias de história e memória, só existe no romance. A estratégia narrativa não é original: muitos escritores inventam personagens famosos com os quais os personagens romanescos convivem. Neste romance, porém, além de vida e concepção poética próprias, o artista plástico fictício tem uma importante função na economia narrativa: ele funciona como um aglutinador dos protagonistas, na medida em que eles só se relacionam por causa de alguma menção a sua vida ou obra. $\mathrm{O}$ artista tem, portanto, uma função estrutural de organização sintática da diegese. Mais do que isso: sua concepção artística inventada pode nos dar pistas de uma leitura criativa sobre a construção da significação no romance.

O romance conta a estória de amor entre Rimini e Sofia e como vivem a separação. Mais do que o presente diegético, a narrativa fala da sobredeterminação do passado

\footnotetext{
${ }^{3}$ O amor zumbi publicado na Revista Veja de 20 de junho de 2007.
}

Disponível em: http://seer.fclar.unesp.br/casa 
dos protagonistas no presente que escolhem viver. $\mathrm{O}$ romance está estruturado em quatro partes, cada uma com um número desigual de capítulos. Cada parte conta o relacionamento de Rimini, com uma mulher, depois da separação de Sofia: Vera, na primeira parte, Carmen, na segunda, Nancy, na terceira e a volta para Sofia, na quarta. As partes não são estanques e as estórias circulam entre uma parte e outra. Há grandes analepses que provocam saltos e recuos na linearidade narrativa. O que une as cenas, costurando-as de maneira a formarem um tecido coeso e bem tramado, é a presença de Rimini, Sofia e o artista plástico Jeremy Riltse.

\subsection{A história de amor e a separação}

A narrativa conta uma estória de amor entre Rimini e Sofia que, depois de doze anos de relacionamento, resolvem se separar. Há poucas notícias de como viviam Rimini e Sofia enquanto casados, espalhadas ao longo da narrativa, misturadas às digressões dos personagens, aos diálogos que se entabulam nas rodas de amigos, ou no esforço descritivo delirante do narrador, preocupado em "esgotar" cada instante, cada gesto, cada lembrança de Rimini. No cap. 07 da primeira parte, o narrador se ocupa de contar um pouco a crença que os protagonistas tinham no amor que viviam:

Acreditavam no modo como se amavam, e essa crença era mais forte que qualquer natureza, qualquer sinal que o mundo lhes dirigisse para desmentilos ou ridicularizá-los. Eram arrogantes e modestos... havia algo de mafioso, um espírito de corpo e uma discrição inflexíveis, ditados pelo amor, mas avivados por uma espécie de medo de catástrofe, em sua maneira de evitar as infiltrações... o amor era uma fortaleza...nenhum dos dois tinha experiência em matéria de armadilhas, traições, triângulos...deviam toda a sua lealdade à situação, aos ideais da situação: amor, confiança, intimidade, respeito, profundidade - essas perfeições pelas quais estavam dispostos a sofrer, a quebrar lanças, a sacrificar tudo.

Quase não pareciam humanos... Viviam nesse além onde vivem os que têm a impressão de participar de uma experiência única, ou viviam a experiência única que vivem os que têm a impressão de participar de um além inacessível para a maioria dos mortais. (PAULS, 2007, p.38-40)

No capítulo seguinte, o narrador conta como se inclui a separação:

Tinham alcançado uma forma rara de perfeição. Viviam no interior de um interior, como nesses ambientes que reproduzem por meios artificiais, entre quatro paredes, atrás de um gigantesco tabique de vidro, para que os visitantes possam admirar seu realismo, a temperatura e a umidade e a pressão e a fauna e a flora de ecossistemas exóticos. Não havia região da bolha que não estivesse recoberta pela membrana. Rimini e Sofia respiravam normalmente, mas o exterior já começava a se tornar um pouco borrado para eles, embaçado pelas velaturas que, ao exalarem, deixavam nas paredes de vidro.

Tinham feito tudo. Defloraram-se; raptaram-se de suas respectivas famílias; viveram e viajaram juntos; juntos sobreviveram à adolescência e depois à juventude e chegaram à vida adulta; juntos foram pais e choraram o

Disponível em: http://seer.fclar.unesp.br/casa 
morto diminuto que nunca chegaram a ver; juntos conheceram professores, amigos, idiomas, trabalhos, prazeres, lugares de veraneio, decepções, costumes, pratos exóticos, doenças - todas as atrações de uma versão prudente, mas versátil, desse misto de surpresa e fugacidade que normalmente se chama vida podia oferecer-lhes... E para que a coleção ficasse completa, definitivamente completa, eles mesmos acrescentaram a peça fundamental: a separação. Como tudo, eles a planejaram juntos, com o cuidado, a dedicação, a minúcia artesanal com que haviam cunhado os troféus do amor ao longo do tempo... se fosse consumada como eles se propunham a consumá-la, amorosamente, era o que lhes permitiria morrer bem; ou seja, em suas palavras, continuar vivendo sem eles no interior da bolha que haviam criado. (PAULS, 2007, p. 47-48)

A maioria das cenas narradas enfoca a vida que levam depois de separados. Ainda que Rimini se relacione depois com Vera - garota consumida pelo ciúme, que morre atropelada depois de flagrar um beijo de Sofia em Rimini - e com Carmen - tradutora com quem se casa e tem o filho Lúcio e de quem também se separa depois que Sofia sequestra o filho - e com Nancy, aluna de tênis, por causa de quem vai parar na cadeia, sendo libertado por Sofia - Rimini nunca deixa de se relacionar com Sofia, para quem volta no fim da estória. Da divisão das coisas que partilhavam quando casados, fica sem dividir apenas um álbum de fotos. Sofia pede que ele faça uma divisão, Rimini adia a tarefa e o álbum completo fica entre os dois, como motivo e pretexto de telefonemas, recados, cartas e encontros. O narrador, em determinado momento, sentencia:

O erro de Rimini fora não decidir nada: ter se limitado a renunciar. De modo que as fotos ficaram ali, estancadas em sua indeterminação, como amuletos que, retirados de circulação, não tivessem outra coisa a fazer a não ser acumular energia e significado. (PAULS, 2007, p.53)

Como o álbum de fotos a circular entre os personagens como um fantasma, fica, também Jeremy Riltse.

\subsection{Estratégias de composição}

A primeira cena da narrativa, como costuma acontecer com os grandes romances, anuncia, de forma emblemática, o que virá. Relendo, retrospectivamente, percebese que a primeira cena subsume uma interpretação da estória como se o narrador, que se apresenta na narrativa como heterodiegético, com focalização interna baseada no ponto de vista de Rimini, nos desse uma preciosa "dica" de como a estória de amor dos protagonistas irá sobredeterminar todas as outras estórias que acontecem na narrativa. Veremos que não se trata de um procedimento que se restringe ao nível das ações; também no nível discursivo perceberemos um efeito de sentido, uma "sombra" que permanecerá ao longo do romance. E uma sombra que resta na intermediação com a lente fotográfica. A narrativa começa com Rimini sendo invadido por uma campainha enquanto toma banho, numa manhã, em sua casa. É o carteiro que lhe entrega uma correspondência. A riqueza de detalhes na descrição da 
correspondência, desde o envelope, vai preparando o narratário sobre a importância do que virá. Cito a cena a partir da abertura da correspondência:

Rimini, na verdade, nem sequer sabia abri-las. Quis rasgar um dos cantos do envelope; algo ofereceu resistência. Rasgou-o com os dentes, com uma fúria canina, e ao cuspir um pedacinho de papel descobriu que mutilara, também, uma parte do conteúdo. Era uma foto colorida: no centro, exposta numa vitrine, havia uma rosa vermelha pousada num modesto pedestal preto; um pouco abaixo, em letras pequenas, mas legíveis, uma placa branca dizia:" In memorian Jeremy Riltse, 1917-1995". Uma rajada escura o sacudiu: umidade, pó, essas alquimias rançosas que de repente começam a se filtrar pela fresta de uma porta. Um pouco de sua inocência desmoronou. Quando virou a foto, Rimini, pressentindo o que encontraria, era menos jovem do que dez segundos antes.

Tinta azul-escura permanente, letra microscópica, penteada para a direita. E a antiga compulsão de abrir parênteses por qualquer motivo. Leu: "Em Londres (como há seis anos), mas agora a janela do apartamento ( alugado de uma mulher chinesa com um curativo no olho) dá para um pátio sem flores onde alguns cães (acho que sempre os mesmos) rasgam todas as noites os sacos de lixo e se pegam por alguns ossos tristes. (Você devia ver a paisagem com a qual acordo todas as manhãs.) Há duas noites um sonho longo e doce me tirou o sono: não me lembro dele, mas você estava lá, ansioso, como sempre, por alguma coisa que não tinha a menor importância. Exatamente enquanto eu sonhava ( soube disso mais tarde), J.R. se matava. As coisas passam; passam por predestinação, sem que ninguém as arrebate. Pode fazer o que quiser com isto. (Estou mudada, Rimini, tão mudada que você não me reconheceria.) Este papel parece feito especialmente para você: tudo o que se escreve nele pode ser apagado com o dedo, sem deixar marcas. Pode ser, mesmo, que estas linhas já tenham desaparecido quando você as receber. Mas nem J.R. nem a foto são culpados de nada. Se estivesse no meu lugar ( e estava: meu sonho jura que estava), você também a teria tirado. A única diferença é que me atrevo a mandá-la. Espero que a jovem Vera não sinta ciúme de um pobre pintor morto. Espero que você saiba ser feliz.. S."

Rimini virou a foto e examinou-a novamente. Reconheceu o museu, e depois, na borda direita, fora do alcance do flash, a sombra de um quadro de Riltse que não se notava antes. Agora a vitrine parecia meio nublada por uma sobreimpressão. Aproximou a foto dos olhos e viu, refletidos no vidro que protegia a rosa, o clarão branco, a pequena câmera automática e, por fim, deslumbrante como uma coroa de luz, o grande halo loiro dos cabelos de Sofia. (PAULS, 2007, p. 12)

A "sobreimpressão" de que fala o narrador é a chave de leitura que vamos acompanhar ao longo da narrativa. Tudo se passa como se à estória que se conta viesse impressa uma sombra da estória patológica do amor de Rimini com Sofia, uma sobreimpressão do passado que interfere, sobredetermina e faz fracassarem as tentativas de recuperação do protagonista. Mas a sobredeterminação não é imediata, embora às vezes a presença física de Sofia interfira nos rumos da narrativa. O que impressiona, como efeito enunciativo, é o jogo de intermediações que se estabelece com as lentes da máquina de fotografia, com a lente da TV, com os quadros do pintor Jeremy Riltse, com os retratos, com os bilhetes que vão se espalhando ao longo da narrativa. Mesmo a própria Sofia vai reinar, 
poderosa, nas sugestões que se desenham no jogo de luzes da narrativa, como se ao ponto de vista de Rimini, que o narrador escolhe focalizar internamente, se somasse, como uma sombra, o ponto de vista de Sofia. A "coroa de luz, o grande halo loiro dos cabelos de Sofia" vai funcionar como uma espécie de epíteto dos heróis épicos, introduzindo, nomeando e acompanhado as aparições da personagem. Às vezes mesmo substituindo o nome, o que cria um belo efeito de fantasma. Eis alguns exemplos:

Rimini, em visita a um amigo no hospital, desmaia ao ver a enfermeira tirar sangue. O narrador conta, assim, a sua volta do desmaio e o encontro com Sofia, que chegava ao quarto, naquele momento: "Uma voz e umas mãos invisíveis resgataram-no de um porão profundo. Deitado de costas no chão, viu uma sombra com uma auréola brilhante, muito loira, que se aproximava e se afastava de seu rosto.”(PAULS, 2007, p.143)

Em outro momento, no palco de um anfiteatro, fazendo tradução simultânea para um conferencista francês que se apresentava, Rimini ouve uma pergunta da platéia. Conta o narrador:

"[Rimini] olhou para o fundo da sala, viu duas ou três cabeças que giravam em direção à coluna, viu a coluna, o braço com a manga - uma "túnica indiana" - e a mão segurando o microfone e depois, como a última peça de dominó que cai, empurrada pela queda de todas as anteriores, uma labareda de flagrantes cabelos loiros: "Não sei se o professor ( e seus colegas europeus, ou os lingüistas em geral, enfim) está a par[...]"(PAULS, 2007, p. 191).

Outra vez, em visita a uma feira de livros, Rimini folheia um livro e encontra uma foto perturbadora. Depois de descrever o autor do livro, conhecido de Rimini, e o momento, o narrador nos descreve a foto que o perturba:

“[...] mais atrás, sentadas no grande sofá estofado de leopardo, duas mulheres conversam e fumam de perfil, segurando a taça e o cigarro com a mesma mão, e um garoto e uma garota mais jovens, alertados pelo relâmpago, viram-se para a câmera com ar hostil: a garota é loira e parece ter chamas na cabeça; o garoto [...]"(PAULS, 2007, p. 215)

a descreve:

Quando está saindo da cadeia, Rimini vê Sofia que o espera. O narrador assim

[...] descolou-se da parede em que estivera esperando, deslizou de perfil entre o pára-choques dos carros e atravessou a rua em direção a ele, a eles, com sua cabeleira em chamas, envolta naquela eterna auréola de claridade que ensombrecia seu rosto, como se estivesse na contraluz." (PAULS, 2007, p. 433)

Nos exemplos citados e em outros que se espalham pela narrativa, a presença de Sofia (e do passado) se interpõe na vida de Rimini, sempre mediatizada por alguma forma de linguagem: ou a linguagem da fotografia, ou a dos bilhetes e cartas, ou por meio da arte de Jeremy Riltse, como veremos a seguir. 


\subsection{Jeremy Riltse - o artista da Sick Art}

Depois da primeira cena em que o artista é apresentado, várias outras atestam a importância do artista entre os protagonistas. Eles o adoravam desde o dia em que descobriram que se amavam, conta-nos o narrador. A primeira viagem que fizeram à Europa foi apenas um pretexto para verem dos originais do mestre. Do início ao fim da narrativa, a obra do artista plástico costura as cenas aparecendo nas casas, nas notícias, nas conversas, nas lembranças e nas digressões do narrador.

Jeremy Ritse faz parte do que o narrador chama de Sick Art. O movimento existe fora dos limites da narrativa. Uma pesquisa rápida confirma que há vários artistas que produzem obras sobre doenças, ou doentes ou obras que poderiam adornar hospitais e clínicas. Trata-se, como se vê, da doença como tema ou como pretexto da produção da arte. No romance, Jeremy Riltse tem um projeto estético bem fundamentado e compõe obras em que inclui alguma parte do próprio corpo que mutila para esse fim estético.

$\mathrm{O}$ artista tem uma série que se chama "História Clínica" que congrega vários trabalhos. "O buraco postiço", "Afta", "Herpes" e "Placa". Pintados, provavelmente por volta de 1991, apresentam-se como um esboço. Segundo o narrador, o pintor, em carta a um mordomo de seu marchand, deixa bem claro que se propõe a inverter a relação entre esboço e obra definitiva. As obras definitivas nunca apareceram, mas os esboços perseguem a idéia de que a arte e o desequilíbrio orgânico são consubstanciais. Vagando pela Europa, Riltse coleciona misérias, perigos, enfermidades, tudo o que possa servir de matéria - prima para a sua arte. De tempos em tempos, quando o estoque atinge certo volume e a necessidade de trabalhar torna-se irresistível, Jeremy Riltse ancora num porão ou casa alugada "qualquer pocilga que amontoe imigrantes" (PAULS, 2007 p.324) e ali, em "ateliês nômades" produz os esboços da série.

Segundo o narrador, a Sick Art, "ao contrário da homeopatia", age de fora para dentro. Pondo em perigo a própria integridade física, Jeremy Riltse prega com um grampeador sobre uma tela uma placa psoríaca, uma pedaço de língua com uma chaga amarelenta ou um botão cor de ameixa que um vírus faz crescer sobre um lábio. Por mais demente que possa parecer, diz o narrador, o risco físico implícito no projeto é diretamente proporcional a sua ambição estética. Outros artistas saquearam as idéias de Jeremy Riltse, mas conseguiram, com suas obras, uma obtusa fachada de provocação, restaurando a velha função curativa - religiosa - da arte, confinando a doença na arte e restaurando a saúde do artista. Jeremy Rilse não. Ele concebe e pratica a Sick Art como um vaivém, uma celebração de reciprocidade. Segundo as explicações do narrador, se Riltse extirpa uma chaga de sua língua e a estampa contra uma tela, não é para se curar; é para que a doença de sua língua mude, derive, passe para outro estado. A chaga já não está lá, mas a doença continua ali, persistindo e alterando-se ao mesmo tempo: a doença é agora a incisão que ocupou o lugar da chaga. $\mathrm{O}$ triunfo da Sick Art não pode ser a saúde do artista, mas a renovação perpétua de sua doença e de sua arte: "artistizar a doença não sem adoentar a arte" (PAULS, 2007, p.326), nos diz o narrador, como a defender Jeremy Riltse.

O que Riltse persegue com a Sick Art é a desproporção, essa combinação letal de heterogeneidade e mudança de escala, que permite romper o "cerco perverso da arte" e "derramar-se" nos lugares comuns da vida social. Andy Warhol, seu contemporâneo, tem a arte evocada em vários aspectos como semelhante à sua, mas seu "conceitualismo seco, desidratado, típico do protestantismo capitalista" (PAULS, 2007, p.328) difere da arte de 
Riltse, com seus excessos sangrentos e sua compulsão camicase e que aparece na voz dos especialistas em arte não como o autor da Sick Art, nem como seu representante mais completo, mas como seu principal e mais devoto paciente e também como sua vítima. $\mathrm{O}$ artista é, ao mesmo tempo, a mente que concebe a idéia, a mão que a executa e a matéria que sofre.

É interessante como, no capítulo em que o narrador mais se deixa levar pelas definições sobre a Sick Art e a vida e obra de Riltse, mais ele próprio, narrador, aparece como enunciador na narrativa. Ao descrever a concepção da obra "O buraco postiço" (que vai ter uma funcionalidade grande na narrativa pois é por causa dele que Rimini irá preso e será libertado por Sofia, voltando para sua casa e para ela), o narrador se demora em detalhes da obra, deixando escapar perguntas e considerações metaficcionais que escancaram a ironia que perpassa por toda a obra. Com perguntas como:

Importa afinar tanto o lápis para esmiuçar a fisiologia sexual de um personagem secundário, por outro lado chamado - mas isso também é secundário - a abandonar a cena em breve, e não da maneira mais elegante do mundo, quando ali mesmo, a menos de um passo, o homem que fez da fisiologia uma arte (e vice-versa) incuba em seu foro mais íntimo o germe do que virá? (PAULS, 2007, p. 332)

Ou, ainda, declarações como: "Não há arte verdadeira que não franqueie o acesso a novas dimensões da experiência. A sentença não é de Riltse nem de ninguém, por isso não admite discussão." (PAULS, 2007, p.332) O narrador, assim, vai “ descaradamente" convocando o narratário a pactuar com ele das convicções que vai construindo sobre as personagens, sobre a arte, assumindo um "nós" que não havia aparecido antes. O escancaramento do ato de narrar atinge o grau máximo, como nos exemplos que citamos a seguir:

Salgo, a quem nosso médico só conhece de vista [...] (PAULS, 2007,p. 336);

[...] assim se afasta o jovem médico do relato, ou assim, para sermos justos, afastam-se seus narradores, que aproveitam esse breve intervalo [...] (PAULS, 2007, p. 338);

Este é o Riltse que deixamos [...] (PAULS, 2007, p. 344);

Tomemos com pinças o exemplar do The Nation [...] (PAULS, 2007, p. 344);

[...] e se um observador menos indolente do que nós tivesse tido o trabalho de examinar de perto a página do jornal [...] (PAULS, 2007, p. 345);

Então ele adentra, ele mesmo, e se deita sobre o tapete sintético e, dando-nos as costas, num gesto de pudor que não saberíamos explica [...] (PAULS, 2007, p. 346);

E enquanto Salgo esquece e é esquecido [...] (PAULS, 2007, p. 350);

[...] um cliente...velho amigo destas páginas, pagou-lhe certa vez [...] (PAULS, 2007,p. 355); 
Vamos nos deter nisso, por favor, antes que os biógrafos o exibam, devidamente abastardo [...] (PAULS, 2007, p. 364);

Saibam disso ou não - e tudo indica que não sabem - a garota e o quadro têm os dias contados. (PAULS, 2007, p. 365)

À medida que o narrador se concentra em Jeremy Riltse, ele se autodetermina ficcionista, romancista, colocando-nos no papel cúmplice de narratários. Passado esse momento, o narrador volta a narrar como antes, oculto sob a aparência de um narrador heterodiegético, com focalização em Rimini, com a "sobreimpressão" de Sofia.

A arte patológica de Riltse parece funcionar para intensificar, de forma icônica, o amor patológico que une os dois protagonistas, como se, ao falar de um, os outros ficassem subentendidos e vice-versa. E também o narrador mostra-se quando mostra Jeremy Riltse e oculta-se, deixando-se entrever como uma "sobreimpressão", quando narra compulsivamente a estória de amor.

\section{Considerações finais}

O romance de Alan Pauls conjuga, de forma sincrética, as linguagens verbal e visual, não porque fale delas mas porque as apresenta, de forma mimética, como estratégia de composição literária. Tirando partido das especificidades de cada uma, o escritor as reúne como a demonstrar que o verdadeiro sentido de narrar é mostrar a palavra fazendo o que diz e contar a pintura dizendo o que faz. A linearidade verbal, que poderia impedir a narração "sobreimpressiva" que acabamos de descrever, obrigando que se falasse de Rimini e depois de Sofia, alcança uma eficácia amplificada com as estratégias emprestadas das artes visuais, como sobreenquadramentos, reflexos por meio de lentes, focalizações em plongée e contra plongée. A pintura de Jeremy Riltse, com sua capacidade icônica, dá a ver a relação patológica dos protagonistas, como a mimetizar, irônica e grotescamente, as mutilações que o amor provoca. Entre esses dois modos de dizer, a arte de Alan Pauls, a traduzir o melhor da literatura contemporânea.

\section{REFERÊNCIAS}

PAULS, A. El pasado. Buenos Aires: Editorial Anagrama, 2003.

O passado. São Paulo: Cosac Naify, 2007.

NETO, M. S. “O amor zumbi”. In: Revista Veja. Ed. 2013, Ano 40, n. ²4, jun. 2007.

Recebido em: 27/07/12

Aprovado em: $15 / 10 / 12$ 